\title{
Optimal Performance of Doubly Fed Induction Generator Wind Farm Using Multi-Objective Genetic Algorithm
}

\author{
Ahmed H. A. Elkasem¹, Salah Kamel ${ }^{1,2}$, Ahmed Rashad ${ }^{3}$, Francisco Jurado ${ }^{4 *}$ \\ ${ }^{1}$ Department of Electrical Engineering, Faculty of Engineering, Aswan University, 81542 Aswan (Egypt) \\ Chongqing, 400030 (China) \\ ${ }^{3}$ Upper Egypt Electricity Distribution Company, Qena Rural Electrification Sector (Egypt) \\ ${ }^{4}$ Department of Electrical Engineering, University of Jaén, 23700 EPS Linares, Jaén (Spain)
}

${ }^{2}$ State Key Laboratory of Power Transmission Equipment \& System Security and New Technology, Chongqing University,

Received 19 October 2018 | Accepted 18 March 2019 | Published 29 March 2019

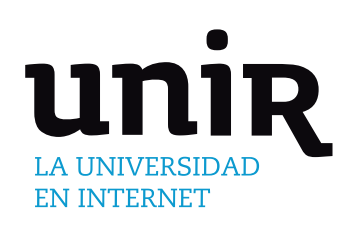

KEYWORDS

DFIG, SCIG, Multi-

Objective Genetic

Algorithm (MOGA).

The main purpose of this paper is allowing doubly fed induction generator wind farms (DFIG), which are connected to power system, to effectively participate in feeding electrical loads. The oscillation in power system is one of the challenges of the interconnection of wind farms to the grid. The model of DFIG contains several gains which need to be achieved with optimal values. This aim can be accomplished using an optimization algorithm in order to obtain the best performance. The multi-objective optimization algorithm is used to determine the optimal control system gains under several objectives. In this paper, a multi-objective genetic algorithm is applied to the DFIG model to determine the optimal values of the gains of DFIG control system. In order to point out the contribution of this work; the performance of optimized DFIG model is compared with the non-optimized model of DFIG. The results show that the optimized model of DFIG has better performance over the non-optimized DFIG model.

\section{INTRODUCTION}

$\mathrm{T}$ $\neg$ HE use of renewable energy in these days became necessary. Wind 1 energy is one of renewable energy resources. Wind energy is a clean energy hence, it is a friend of the environment and human. This will decrease the releasing of harmful gases such as (CO2). These harmful gases are emitted from the conventional generation stations. Wind energy has several advantages such as cost-effective, a clean fuel source, does not pollute the air like power plants which rely on combustion of fossil fuels, such as coal or natural gas, which emit particulate matter, nitrogen oxides, and sulfur dioxide causing human health problems and economic damages, also does not produce atmospheric emissions that cause acid rain and smog [1]. The first appearance of wind farms was based on the squirrel cage induction generator (SCIG). The second appearance of wind farms was based on DFIG. The DFIG is a wound rotor induction machine hence it can operate in super-synchronous, sub-synchronous speed and unity power factor manner [2]. The active power from DFIG is produced from the captured mechanical energy which obtained from wind energy [3].

The benefits of the DFIG over SCIG are to improve power quality and to reduce mechanical stress. The optimization algorithm can be single objective or multi-objective. All single-objective optimization methods can find the solution of one specific control problem. This solution differs according to the change in the objective of the same control problem $[4,5]$.

* Corresponding author.

E-mail address: fjurado@ujaen.es
The occurrence of power system oscillation could cause instability of DFIG wind farm and hence, of connected grid. According to the new optimization techniques that applied to achieve the optimal controller parameters, system stability and good performance are achieved. The improvement of the performance of DFIG wind farms using singleobjective optimization technique has been presented in $[6,7]$. The improvement of the performance of DFIG wind farms using multiobjective genetic algorithm was investigated in [8]. Many researchers have achieved for enhancing the generated active power $[9,10]$. In [11], the dynamic performance of DFIG has been well improved by achieving the optimal controller parameters. The output power from DFIG has been enhanced to help in system stability [12]. This paper aims to enhance the generated active power of DFIG and effective load frequency control with different power system areas. The optimized active power that connected to grid is produced via optimized controller parameters in the studied system. Hence, the oscillation and short settling time will be reduced. This paper represents the basis of DFIG working with power systems which are used in different applications. The control parameters of DFIG are investigated using MOGA. The simulation is carried out in two cases. Firstly, DFIG model performance without MOGA. Secondly, the performance of DFIG model with MOGA.

\section{Multi-ObJective Optimization}

\section{A. Genetic Algorithm (GA)}

The evolutionary Theory is the basis of GA working method. The process of finding the optimal solution using GA is composed of 
three stages. Selection or reproduction represents the first stage and it can be defined as the process of choosing the sets of parents from the population. Crossover is the second stage and it can be defined as the process of choosing two parent solutions from the selected sets. Mutation is the last stage of GA; in this process of generating the next generation from the selected parents $[13,14]$. There are many papers studied the enhancement of DFIG based on single-objective optimization like using craziness-based particle swarm optimization (CRPSO) [13]. The energy of wind turbine and power factor have been enhanced using evolutionary computation algorithm (ECA) [15].

\section{B. Multi-Objective Optimization Technique (MOO)}

This optimization technique includes a set of several objectives that need to be achieved. All objectives are gained without overlapping between them. These objectives can be written in the form of functions; these functions can be written as shown in (1).

$$
F(x)=\left[f_{1}(x), f_{2}(x), f_{3}(x) \cdots f_{i}(x)\right]
$$

The variables of the objective function are denoted by (x) where $x=\left(x_{1}, x_{2} \ldots x_{n}\right)^{T} \in X$ and the solution is represented by the vector of $\mathrm{X}$. The role of multi-objective genetic algorithm is obtaining the fit solution. This solution must be suitable to a specific set of objectives and it is not requisite to be fit with single object [16]. The main objectives presented in this work are reducing the oscillation in active power wave form and reducing settling time to enhance performance of power system application.

\section{WIND TURBINE MODEL}

In this study a GE 3.6 MW is modeled using MATLAB Simulink program, all data are according to Ref [17]. The block diagram of wind turbine containing modeling of induction generator is shown in Fig. 1.

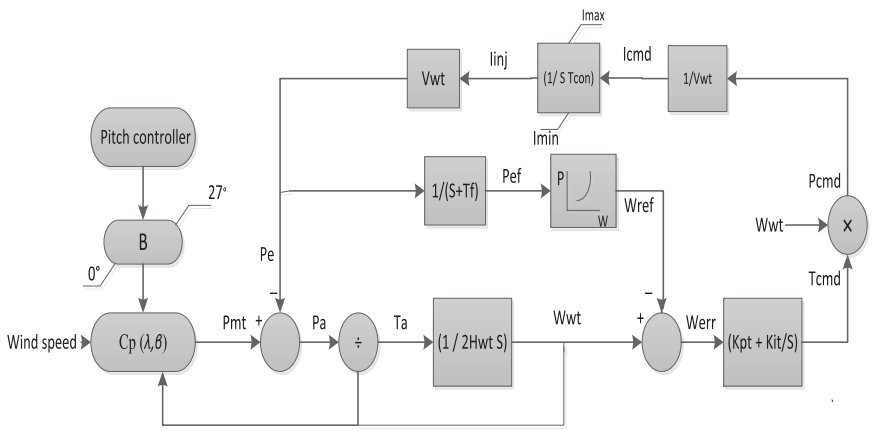

Fig.1. Variable speed wind turbine block diagram.

The captured power by the rotor of wind turbine of doubly fed induction generator from the wind is given by (2) [18] :

$$
\left\{\begin{array}{c}
P_{w t}=\frac{1}{2} \pi r^{2} \rho v^{3} C_{p}(\lambda, \beta) \\
C_{p}(\lambda, \beta)=0.517\left(\frac{116}{\lambda_{i}}-0.4 \beta-5\right) e^{\frac{-0.0068}{\lambda_{i}}}+0.0068 \lambda \\
\frac{116}{\lambda_{i}}=\frac{1}{\lambda+0.08 \beta}-\frac{0.035}{\beta^{3}+1} \\
\lambda=\omega_{0} r \frac{\omega_{w t}}{v}
\end{array}\right.
$$

$P_{w t}$ is referring to power in watts, $\rho$ is referring to the density of air, $r$ is the radius of the turbine rotor (blade-length that equals to $52 \mathrm{~m}), \mathrm{v}$ is referring to the wind speed. $C_{p}$ represents the power coefficient (betz coefficient). Betz coefficient reaches maximum value $=0.5173$, in fact the obtainable power coefficient is in the range of $45 \%$ according to pitch angle $\beta$ and the tip speed ratio $\lambda$. The optimal tip speed ratio is equal to $\lambda_{o p t}=8.76 \omega_{w t}$, where $\omega_{w t}$ is referring to the rotor speed in pu. $\omega_{0}$ is the rotor based speed in $\mathrm{Rad} / \mathrm{s}$, its value is equal to $1.33 \mathrm{rad} / \mathrm{s}$. $\left(\omega_{\text {ref }}\right)$ is referring to reference speed associated with maximum power tracking in pu. It depends on the measured electric power $\left(p_{e f}\right) ; \omega_{\text {ref }}$ can be computed according to the following equation:

$$
\omega_{\text {ref }}=-0.67 p_{\text {ref }}^{2}+1.42 p_{\text {ref }}+051
$$

where $\mathrm{p}_{\text {ref }}$ is the measured electrical power in pu.

The reference speed calculated by (3) is around $1.2 \mathrm{pu}$ when the generated power levels are above $0.75 \mathrm{pu}$. In this limit (above 0.75 $\mathrm{pu}$ ), the pitch controller begins to reset and adjust the speed in order to generate the maximum power $1.0 \mathrm{pu}$. The pitch angle control is used to keep the generated power within the normal limit. The pitch angle control is applied to DFIG as shown in Fig. 2.

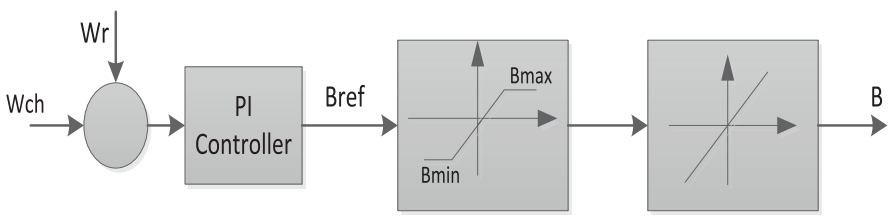

Fig. 2. Strategy of pitch angle control system.

With the increase in wind speed above its rated value, the pitch angle control system role will start increasing in $\beta$ to its maximum value $\beta{ }_{\max }$. Thereby, power capture from the wind return to reference output power [19].

Fig. 3 shows the schematic diagram of DFIG connected to grid [20]. The converters of the DFIG are connected between the rotor and the electrical grid. The stator of DFIG is attached to the power system directly to feed grid with generated power.

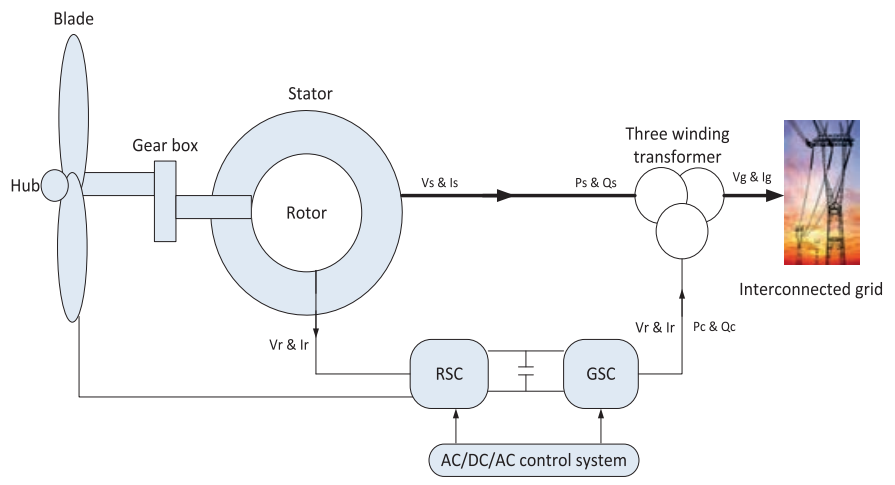

Fig. 3. Schematic diagram of DFIG.

The curves of $C_{p}$ of the turbine according to (2) are plotted for five values of $\beta[\beta=(0,1,3,5,10)]$. The power coefficient reaches maximum value at pitch angle equal to zero $\beta=0$ whenever. With the increase in the pitch angle value, the power coefficient value will be decreased as shown in Fig. 4. 


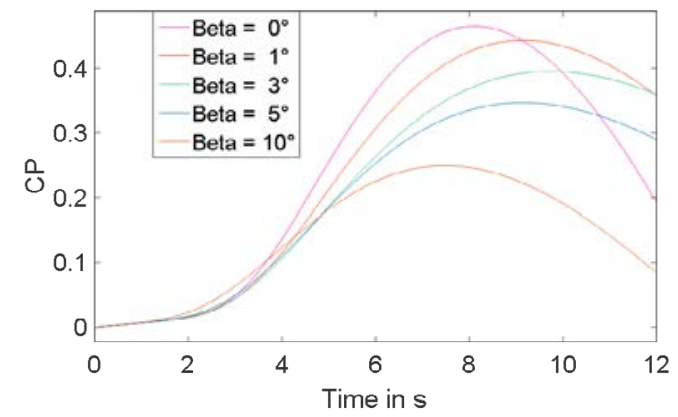

Fig. 4. $C_{p} \rightarrow \lambda$ Curve of GE wind turbine for different pitch angles.

\section{Model of DFIG STUDIED System}

As it has been mentioned before, the first case represents the DFIG model without using a MOGA. This model has been modeled according to Ref [21] and it is shown in Fig.5. This studied model includes non-optimized controller parameters such as $T_{f}$ which gives the power reference, $P_{e f}$ extracts the speed reference $W_{e f}$. The controller parameter for obtaining the injected current to rotor of DFIG is $T_{\text {con }}$ The speed controller gains are divided into proportional gain $K_{p t}$ and integral gain $K_{i t}$.

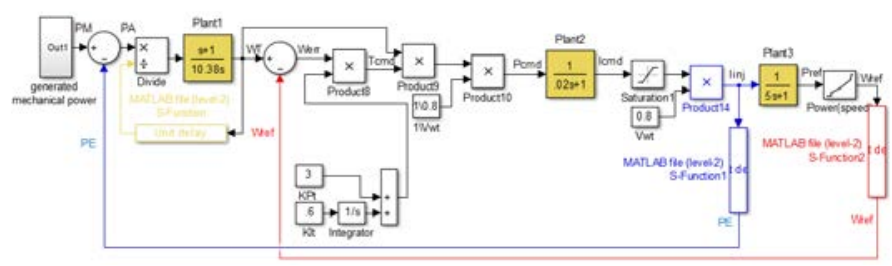

Fig. 5. The model of DFIG without using MOGA technique.

The gains of the non-optimized DFIG wind turbine model are given in Table I.

TABLE I. Gains of Non-Optimized Dfig Model (Without Using Moga)

\begin{tabular}{ccc}
\hline Symbol & Quantity & Values \\
$H_{w t}$ & The inertia of WT & $5.19 \mathrm{~s}$ \\
$T_{f}$ & WT control parameter for obtaining $P_{e f}$ & $5 \mathrm{~s}$ \\
$T_{c o n}$ & WT control parameter for obtaining $i_{i n j}$ & $0.02 \mathrm{~s}$ \\
$K_{p t}$ & Proportional gain & 3 \\
$K_{i t}$ & Integral gain & 0.6 \\
\hline
\end{tabular}

The second case represents the model of DFIG with MOGA. The model of DFIG with MOGA is shown in Fig. 6.

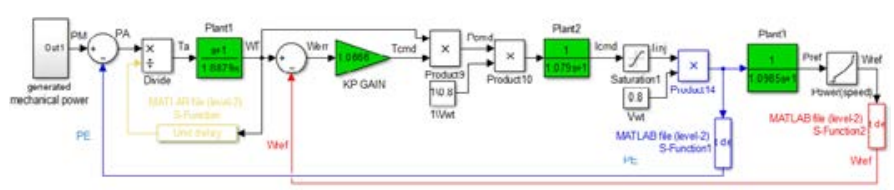

Fig. 6. The model of DFIG using MOGA technique.

The optimized studied model contains transfer functions which are responsible for obtaining a good performance with less perturbations when achieving the best control parameters.

Fig. 7 shows the flowchart of MOGA which is applied on the DFIG model.

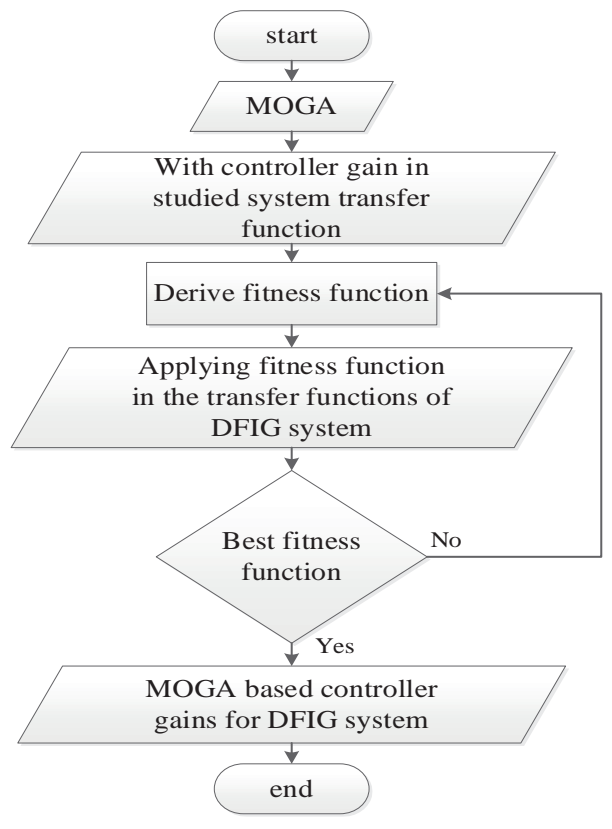

Fig. 7. Flow chart of MOGA based controller gain.

The MOGA is based on the fitness function shown in the next equation:

$$
F=\left\{\begin{array}{l}
f_{1}=\int_{0}^{t}(\Delta \omega)^{2} d t \\
f_{2}=\int_{0}^{t}\left(u_{\text {out }}\right)^{2} d t
\end{array}\right.
$$

Where $F$ consists of two objectives $f_{1}$ and $f_{2}$. $f_{1}$ is minimizing the error signal of speed deviation $(\Delta \omega)$ from 0 time to the duration time of simulation $(t) . f_{2}$ is maximizing the output signal of DFIG from 0 time to the duration time of simulation $(t)$. The included control parameters in studied model can be restricted to certain limits by specifying simple bound constrains to the constrained optimizer function. For fmincon, the command is

x= fmincon (@objfun, x0, [], [], [], [], lb, ub, @confun, options);

which limits $\mathrm{x}$ to be within the range $\mathrm{lb}<=\mathrm{x}<=\mathrm{ub}$. To restrict $\mathrm{x}$ (control parameters) to be greater than zero (i.e., $x 1 \geq 0, x 2 \geq 0, x 3 \geq 0$, $\mathrm{x} 4 \geq 0, \ldots$ ), these commands are used [22]:

a) $\mathrm{X} 0=\left[\begin{array}{llll}0.1 & 0.1 & 0.1 & 0.1\end{array}\right]$ this command makes a starting guess at the solution.

b) $\mathrm{Lb}=\left[\begin{array}{llll}0 & 0 & 0 & 0\end{array}\right]$ this order includes the lower boundaries of controller gains in studied model.

c) $\mathrm{Ub}=[]$ there are not any upper boundaries constrains.

The main steps which are related to MOGA technique for achieving the best controller parameters are mentioned as:

Step 1: write an M-file name at MATLAB script:

a) Function $F=\operatorname{tracklsq}(x 1, x 2, x 3, \ldots)$ where $F$ is the function which presents the object, tracklsq is the name of M-file that will be stored and $(\mathrm{x} 1, \mathrm{x} 2, \mathrm{x} 3, \ldots)$ are the variables of the function.

b) To move variables into model parameters, this order must be added $\mathrm{kp} 1=\mathrm{x}(1), \mathrm{kp} 2=\mathrm{x}(2), \mathrm{kp} 3=\mathrm{x}(3)$.

c) For choosing solver and set model workspace to this function, the next command needs to be written as mentioned: -

opt = simset('solver','ode5','SrcWorkspace','Current');

d) For running Simulink model, this command must be added: - [tout, xout, yout] = sim ('optsim', [0 40], opt); where tout, xout and yout 
are the optimized objectives, (sim) is MATLAB command used to run the simulation, (optsim) is the name of the Simulink model and [0 40] is the running time of simulation.

e) At the end, determination of what is the function such as: -

$\mathrm{F}=$ [tout, xout, yout], where tout, xout, yout are the objective functions that need to be modified for a good performance.

Step 2: doing the optimization M-file in new MATLAB script and detecting the best method for minimizing output errors and enhancing the performance of studied model by obtaining best controller parameters. The optimal values of gains of the model of DFIG wind turbine which have been obtained by MOGA are given in Table II.

TABLE II. Gains of Non-Optimized Dfig Model (With Using Moga)

\begin{tabular}{ccc}
\hline \hline Symbol & Quantity & Values \\
$H_{w t}$ & The inertia of WT & $1.0879 \mathrm{~s}$ \\
$T_{f}$ & WT control parameter for obtaining $P_{e f}$ & $1.0985 \mathrm{~s}$ \\
$T_{c o n}$ & WT control parameter for obtaining $i_{i n j}$ & $1.0791 \mathrm{~s}$ \\
$k_{p}$ & Proportional gain & 1.0866 \\
\hline
\end{tabular}

\section{Simulation Results}

The simulation results are carried out in two cases. The first case represents the effect of the change in wind speed on the DFIG wind turbine model without using optimization. The second case represents the effect of the change in wind speed on the model of DFIG with MOGA. The applied wind speed is changed from $(0.1 \mathrm{~m} / \mathrm{s})$ to $(16 \mathrm{~m} / \mathrm{s})$ as shown in Fig. 8.

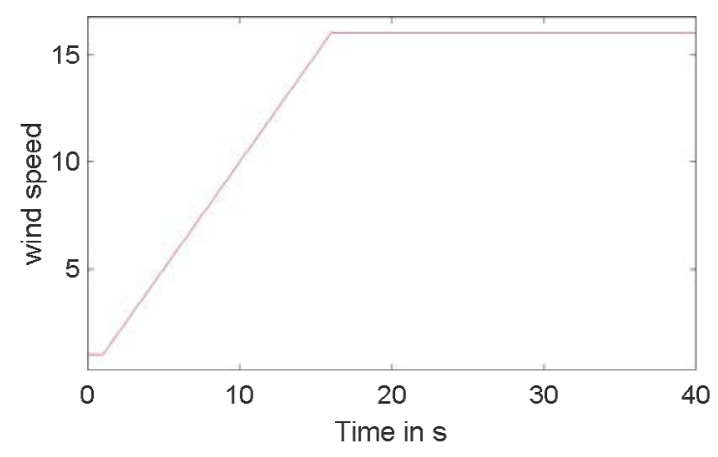

Fig. 8. The variation of the applied wind speed.

\section{1) DFIG Model Results Without MOGA Method}

Fig. 9 shows the impact of the applied wind speed on the pitch angle. As it can be observed from Fig. 9, the pitch angle has varied from (0 degree) to (27 degree).

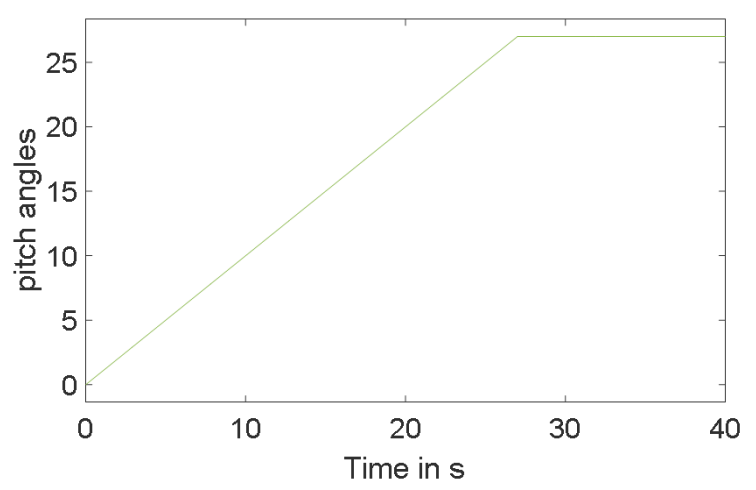

Fig. 9. The pitch angle during the change in wind speed.
Fig. 10 (a) represents captured mechanical power. As shown in Fig. 10 (a), there is no oscillation in $\mathrm{p}_{\mathrm{m}}$. Fig 10 (b) shows the electrical output power $\left(\mathrm{p}_{\mathrm{e}}\right)$. Fig 10 (b) shows that the electrical output power wave has an oscillation at the beginning. This oscillation takes almost 2 seconds (unstable in $P_{e}$ wave form). Also, the value of oscillation is large and its duration is long. According to the oscillation in the extracted active power of DFIG, the power system performance will not be stable. System instability is summarized in fluctuations in system frequency which it supposed to be in steady state case. Fig.10 (c) shows the value of $\left(P_{a}\right)$ where $\mathrm{p}_{\mathrm{a}}$ is the difference between $\mathrm{p}_{\mathrm{m}}$ and $\mathrm{p}_{\mathrm{e}}$. This oscillation occurs due to the absence of optimized controller gains values.

In Fig. 11 the reference power curve takes more than $20 \mathrm{~s}$ to reach the steady state value. Fig. 12 shows the reference wind speed. As shown in Fig. 12 the reference wind speed takes a period to reach the reference value $(1 \mathrm{pu})$. This means that the non-optimized model of DFIG takes a long time to reach stability.

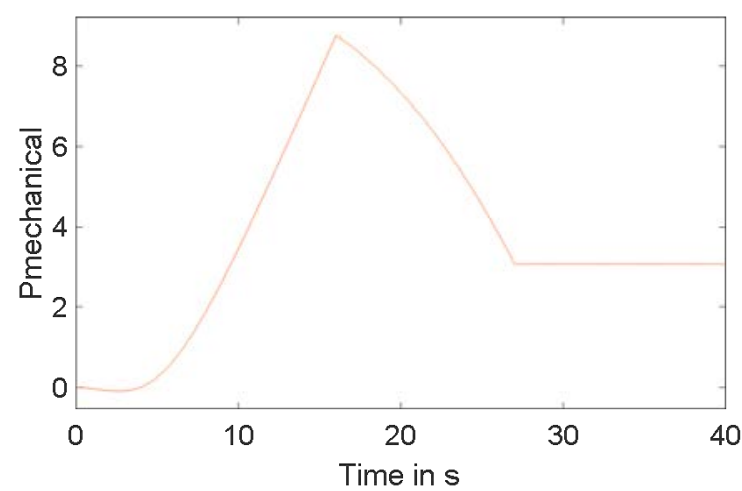

(a)

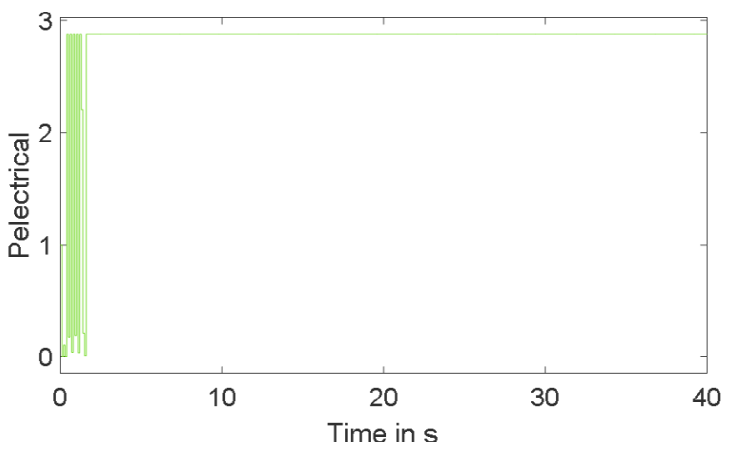

(b)

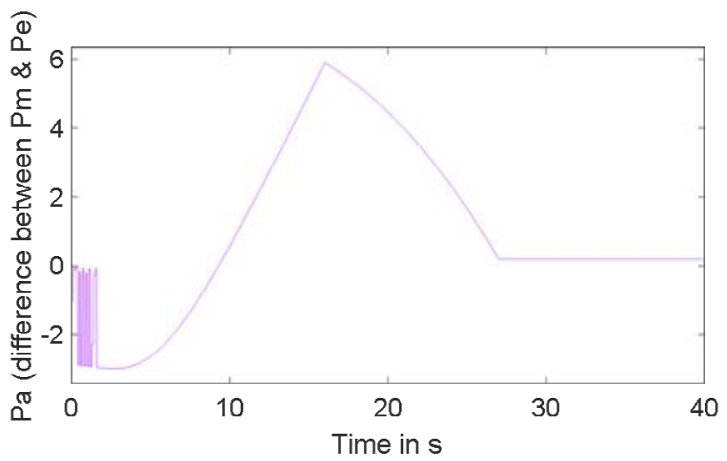

(c)

Fig. 10. Power of Non-optimized DFIG model (a) $p_{m}$, (b) $p_{e}$ and (c) $p_{a}$. 


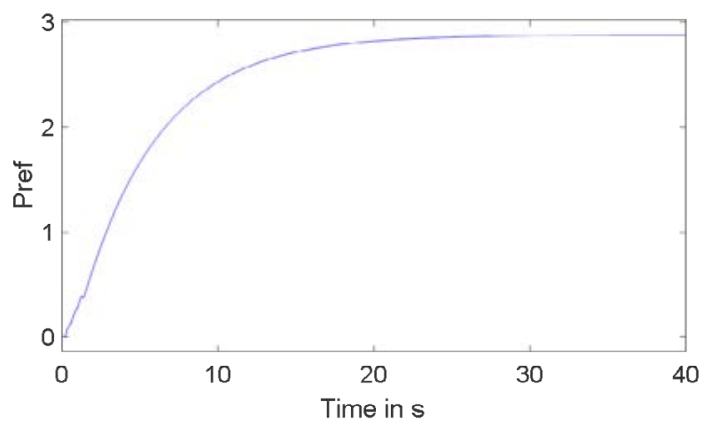

Fig. 11. The reference power $P_{\text {ref }}$.

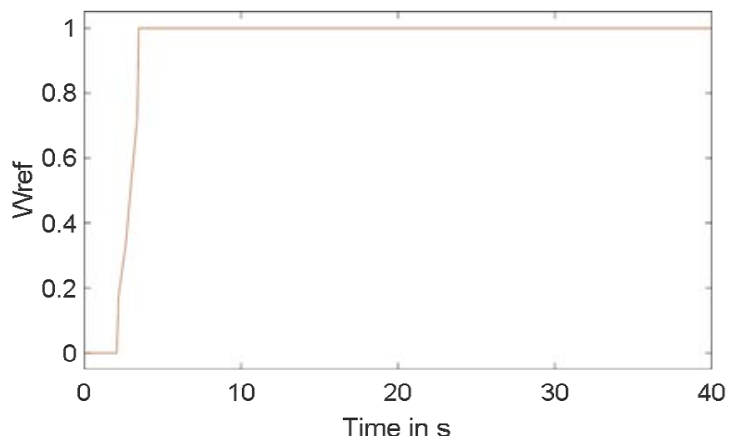

Fig. 12. The reference wind speed $W_{\text {ref }}$.

\section{2) (DFIG) Model Results with (MOO) Method}

Fig. 13 shows the power of the model of DFIG with MOGA: $p_{m}, p_{e}$ and $p_{a}$. As shown in this figure, oscillation in $p_{e}$ and $p_{a}$ are decreased to be very small value compared to non-optimized model. Not only that, the time of oscillation occurring became very small. This will lead to more stability of model and more reliability.

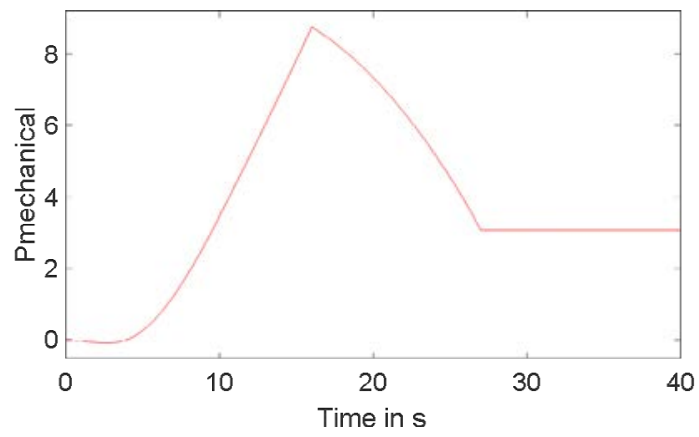

(a)

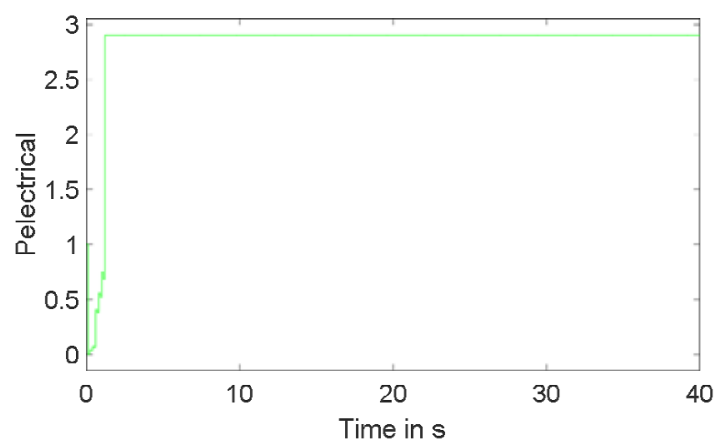

(b)

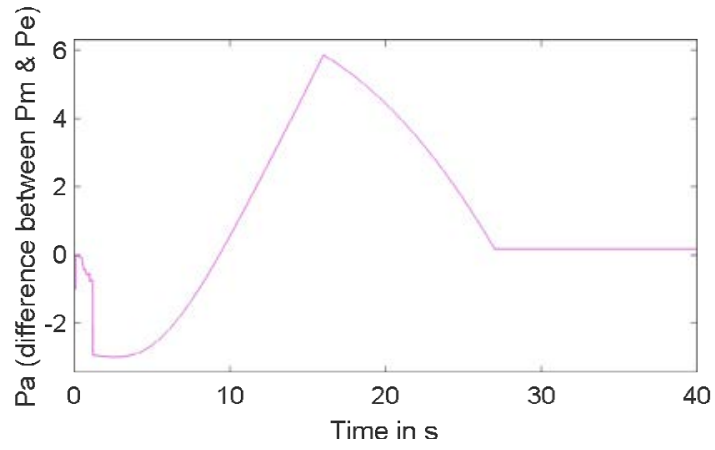

(c)

Fig. 13. The power of model of DFIG with MOGA: (a) $p_{m}$, (b) $p_{e}$ and (c) $p_{a}$.

There is an effective performance of power system operation with optimized generated active power participation. In the case of DFIG participation to enhance the frequency of power system, good results are achieved with enhanced active power which are characterized by lowest perturbations with smallest settling time.

Fig. 14 shows the reference power $\mathrm{p}_{\text {ref }}$ of the model of DFIG with MOGA. Fig. 15 shows the reference wind speed of the model of DFIG with MOGA.

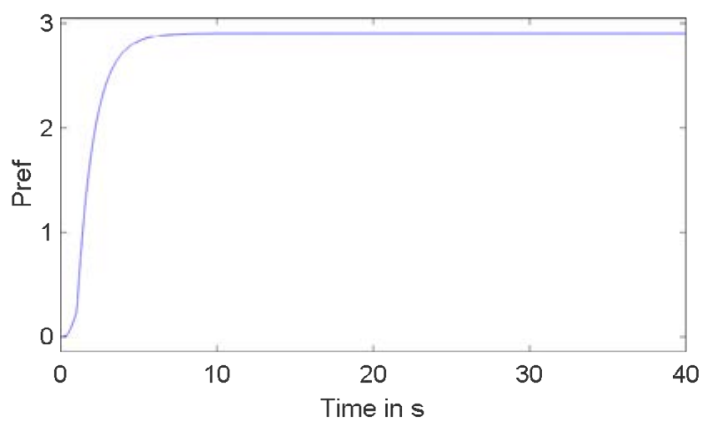

Fig. 14. The reference power $\mathrm{p}_{\text {ref }}$ of the model of DFIG with MOGA.

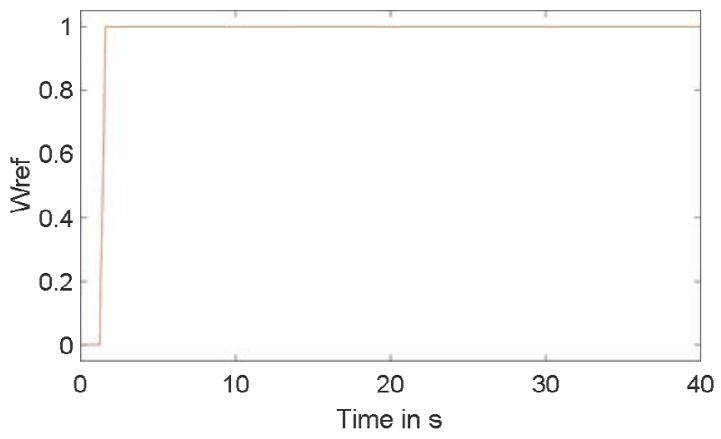

Fig. 15. The reference wind speed of model of DFIG with MOGA.

By comparing Fig. 14 with Fig. 11, it can be observed that pref of the model of DFIG takes lower than 2 s to reach the steady state value while in case of non-optimized DFIG it takes more than $20 \mathrm{~s}$ to reach the steady state value. Also, by comparing Fig. 15 with Fig. 12, it can be observed that in case of DFIG with MOGA the reference wind speed has reached its steady state much faster than in case of non- optimized DFIG.

\section{CONCLUSION}

In this paper, the model of DFIG wind turbines has been based on the optimal value of control gains of DFIG. The optimal value of control gains of DFIG has been investigated using MOGA. The performance 
of the model (DFIG with MOGA) has been examined during wind speed variation as ramp function. The performance of the model of DFIG with MOGA has been compared with the performance of nonoptimized model of DFIG.

From simulation results, it can be concluded that the model of DFIG with MOGA has much lower oscillation in electrical power and both the reference power and reference wind speed reach their steady state level much faster than non-optimized model of DFIG. This will lead to make DFIG wind turbines more stable and more reliable.

\section{REFERENCES}

[1] O. Ellabban, H. Abu-Rub, and F. Blaabjerg, "Renewable energy resources: Current status, future prospects and their enabling technology," Renewable and Sustainable Energy Reviews, vol. 39, pp. 748-764, 2014.

[2] Y. Zou, M. Elbuluk, and Y. Sozer, "A complete modeling and simulation of induction generator wind power systems," in Industry Applications Society Annual Meeting (IAS), 2010 IEEE, 2010, pp. 1-8.

[3] S. Muller, M. Deicke, and R. W. De Doncker, "Doubly fed induction generator systems for wind turbines," IEEE Industry applications magazine, vol. 8, pp. 26-33, 2002.

[4] C. A. C. Coello, "A comprehensive survey of evolutionary-based multiobjective optimization techniques," Knowledge and Information systems, vol. 1, pp. 269-308, 1999.

[5] K. Deb and M.-O. O. U. E. Algorithms, "vol. 16," ed: John Wiley \& Sons, 2001.

[6] Y. Tang, P. Ju, H. He, C. Qin, and F. Wu, "Optimized Control of DFIGBased Wind Generation Using Sensitivity Analysis and Particle Swarm Optimization," IEEE Trans. Smart Grid, vol. 4, pp. 509-520, 2013.

[7] O. P. Bharti, R. Saket, and S. Nagar, "Controller Design of DFIG Based Wind Turbine by Using Evolutionary Soft Computational Techniques," Engineering, Technology \& Applied Science Research, vol. 7, pp. 17321736, 2017.

[8] J. P. Vieira, M. V. Nunes, and U. H. Bezerra, "Using Genetic Algorithm to Obtain Optimal Controllers for the DFIG Converters to Enhance Power System Operational Security," in Wind Turbines, ed: InTech, 2011.

[9] N. A. Janssens, G. Lambin, and N. Bragard, "Active power control strategies of DFIG wind turbines," in Power Tech, 2007 IEEE Lausanne, 2007, pp. 516-521.

[10] L. Xu, "Enhanced control and operation of DFIG-based wind farms during network unbalance," IEEE Transactions on Energy Conversion, vol. 23, pp. 1073-1081, 2008.

[11] L. Yang, G.-Y. Yang, Z. Xu, Z. Y. Dong, K. P. Wong, and X. Ma, “Optimal controller design of a doubly-fed induction generator wind turbine system for small signal stability enhancement," IET generation, transmission \& distribution, vol. 4, pp. 579-597, 2010.

[12] F. Wu, X.-P. Zhang, P. Ju, and M. J. Sterling, "Decentralized nonlinear control of wind turbine with doubly fed induction generator," IEEE Transactions on Power Systems, vol. 23, pp. 613-621, 2008.

[13] P. Bhatt, R. Roy, and S. Ghoshal, "Dynamic participation of doubly fed induction generator in automatic generation control," Renewable Energy, vol. 36, pp. 1203-1213, 2011.

[14] P. Sravanthi, K. R. Rani, J. Amarnath, and S. Kamakshaiah, "Critical clearing time and transient stability analysis of SCIG based wind farm with STATCOM," in Smart Electric Grid (ISEG), 2014 International Conference on, 2014, pp. 1-8.

[15] A. Kusiak and H. Zheng, "Optimization of wind turbine energy and power factor with an evolutionary computation algorithm," Energy, vol. 35, pp. 1324-1332, 2010.

[16] R. Khezri and H. Bevrani, "Voltage performance enhancement of DFIGbased wind farms integrated in large-scale power systems: Coordinated AVR and PSS," International Journal of Electrical Power \& Energy Systems, vol. 73, pp. 400-410, 2015.

[17] N. W. Miller, W. W. Price, and J. J. Sanchez-Gasca, "Dynamic modeling of GE 1.5 and 3.6 wind turbine-generators," GE-Power systems energy consulting, 2003.

[18] B. Wu, Y. Lang, N. Zargari, and S. Kouro, Power conversion and control of wind energy systems vol. 76: John Wiley \& Sons, 2011.

[19] A. M. Rashad and S. Kamel, "Enhancement of Hybrid Wind Farm performance using tuned SSSC based on Multi-Objective Genetic Algorithm," in Power Systems Conference (MEPCON), 2016 Eighteenth International Middle East, 2016, pp. 786-791.

[20] В. Дьяконов, Simulink. Самоучитель: Litres, 2017.

[21] N. R. Ullah, T. Thiringer, and D. Karlsson, "Temporary primary frequency control support by variable speed wind turbines - Potential and applications," IEEE Transactions on Power Systems, vol. 23, pp. 601-612, 2008.

[22] J. F. Sturm, "Using SeDuMi 1.02, a MATLAB toolbox for optimization over symmetric cones," Optimization methods and software, vol. 11, pp. $625-653,1999$

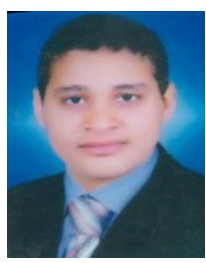

Ahmed. H. A. Elkasem

Ahmed H. A. Elkasem received the B.Eng. from Faculty of Energy Engineering, Aswan University, Egypt in 2014. $\mathrm{He}$ is currently pursuing his MSc degree in Department of Electrical Engineering, Aswan Faculty of Engineering, Aswan University. His research activities include renewable energy and power system optimization.

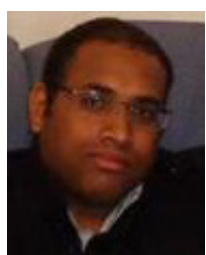

\section{Salah Kamel}

Salah Kamel received the international $\mathrm{PhD}$ degree from University of Jaen, Spain (Main) and Aalborg University, Denmark (Host) in Jan. 2014. He is an Assistant Professor in Electrical Engineering Department, Aswan University. Also, He is a Leader for power systems research group in the Advanced Power Systems Research Laboratory (APSR Lab), Aswan, Egypt. He is currently a Postdoctoral Research Fellow in State Key Laboratory of Power Transmission Equipment and System Security and New Technology, School of Electrical Engineering, Chongqing University, Chongqing, China. His research activities include power system modeling, analysis and simulation, and applications of power electronics to power systems and power quality.

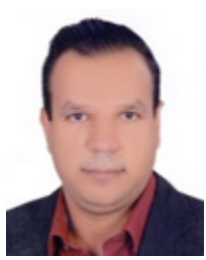

\section{Ahmed Rashad}

Ahmed Rashad received the B.Eng. from Faculty of Energy Engineering, Aswan University, Egypt and M.Sc. degree in electrical power engineering from Faculty of Engineering, South Valley University, Egypt in 2013. He received the jointly-supervised PhD degree in Department of Electrical Engineering, Aswan Faculty of Engineering, Aswan University, Egypt and University of Jaen, Spain in 2018. His research activities include Power system modeling, analysis and simulation, renewable energy and smart grid technologies, applications of power electronics to power systems and power quality.

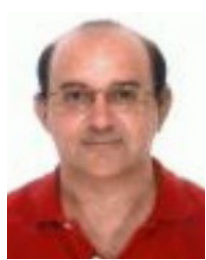

\section{Francisco Jurado}

Francisco Jurado obtained the MSc and $\mathrm{PhD}$ degrees from the UNED, Madrid, Spain, in 1995 and 1999 respectively. $\mathrm{He}$ is Full Professor at the Department of Electrical Engineering of the University of Jaén, Spain. His research activities have focused on two topics: power systems and renewable energy. 